\title{
Multidisciplinary Team Research as an Innovation Engine in Knowledge-Based Transition Economies and Implication for Asian Countries
}

From the Perspective of the Science of Team Science

Yong-gil Lee $^{1}$

This work identifies the key factors influencing the success of multidisciplinary, interdisciplinary, and trans-disciplinary $R \& D$ projects in transition economies by integrating knowledge management, organizational, inter/intra-collaboration (open-innovation), and leadership perspectives, while also addressing the perspective of the science of team science, which is an integrative approach to $R \& D$. This is followed by providing the major sub-constructs of team science and policy implications to better facilitate multidisciplinary, interdisciplinary, and transdisciplinary $R \& D$ projects in knowledge-based transition economies.

\section{Introduction}

The term "team science" was first used in the 2008 special issue (Vol. 35, No. 2S) of the American Journal of Preventive Medicine. In this issue, various team science theories and applications were introduced, particularly in the field of clinical research. The science of team science is a field representing a crossroad between organizational management research and technology and innovation management research. This field requires methodological collaboration between organizational science and innovation management. In the $21^{\text {st }}$ century, scientific, technological, and social issues have been increasingly complicated, and therefore a single promising approach cannot fully address all these problems. This suggests a need for the integration of various disciplines. Physical or mechanical integration is not a good option. However, modern social and technological problems require an integrated approach from various perspectives. What we propose here is an urgent need for transdisciplinary research arising from the complexities of scientific problems and social agendas.

From the 1980s to the 1990s, the major drivers of economic growth came from industries, including capital, huge plants, and skilled workers. However, in a knowledge-based economy, $\mathrm{R} \& \mathrm{D}$ laboratories and various communities of innovation (COIs) have become the key drivers. $\mathrm{R} \& \mathrm{D}$ organizations of multinational firms, universities, and national labs and the concept of the "Triple Helix" have played increasingly important roles in economic growth. This work consid-

\footnotetext{
${ }^{1}$ Department of Energy Resources Engineering, Inha University, 100 Inharo, Nam-gu, Incheon 402-751, South Korea. E-mail: leedomingo@inha.ac.kr
} 
ers team science as a good operating principle for modern economic growth engines (R\&D laboratories), particularly in transition economies.

\section{Modern Innovation Trends in Transition Economies}

Types of innovations can be classified into various categories. Those from standard-based innovation are typical in IT, and innovations in biotechnology and pharmaceuticals are generally based on scientific discoveries through intensive R\&D. Customer- or user-oriented innovations are typical in electronic products and automobiles (Bettencourt \& Ulwick, 2008; Lee et al., 2008).

In general, there are two major types of innovations: continuous improvement through learning by doing and creative destruction, i.e., disruptive innovation. The former reflects commitment to well-defined and expected innovation pathways, whereas in the latter, considerable flexibility keeps innovation options open (Faems et al., 2005; Lee et al, 2009; Lee, 2012). In addition, these two differ in the following ways: convergent vs. divergent behaviors, exploitation vs. exploration, and path following vs. path creation. These two types of innovation lie at the core of the duality of innovation behavior (Faems et al., 2005; Lee, 2010). Previous research has suggested that transition economies often witness both continuous innovation and incremental innovation (Mintzberg, 2007; Lee, 2009). However, path-skipping or path-creating innovation now tends to co-occur with path-following innovation in transition economies.

The motivation behind multidisciplinary, interdisciplinary, or transdisciplinary research is more closely related to path-creating innovation than to the other two forms of innovation. Pathcreating innovation can be an important motive for multidisciplinary, interdisciplinary, and transdisciplinary $\mathrm{R} \& \mathrm{D}$ projects in transition economies, and this $\mathrm{R} \& \mathrm{D}$ behavior seeks to avoid homogeneous group thinking. This work addresses the major sub-constructs of team science, which can facilitate multidisciplinary, interdisciplinary, and transdisciplinary R\&D. R\&D leadership, team cultures, institutional complementarity, intrinsic motivation, and other factors are currently being addressed by $\mathrm{R} \& \mathrm{D}$ labs in transition economies.

\section{Innovation Leadership Nurturing Multidisciplinary and Transdisciplinary Research}

\section{R\&D Leaders' Integrative Perspectives and Insights}

The task of senior R\&D leaders is somewhat fragmented and scattered in nature. Large $R \& D$ programs tend to be complex and consist of a number of seemingly unrelated projects, and this can be seen in the fields of systems biology, nanotechnology, and space technology, among others. Therefore, such large-scale R\&D programs generally involve independent projects that are seemingly unrelated. However, insightful R\&D leaders can offer clear direction for numerous R\&D projects under a given program and align them according to their value, vision, and systematic domain, thereby contributing to society through research and solution development (R\&SD). Successful R\&D leaders are likely to struggle with their strategic direction when faced with transdisciplinary or multidisciplinary research and seldom address problems in isolation. In addition, they deal with the flow (Peters, 1979).

Fragmentation is normal, probably inevitable, and usually sensible in the management of large and complex R\&D programs. The task of senior R\&D leaders is not to impose some abstract order on an inherently disorderly process but to become adept at nudging a program to- 
ward a solution and controlling its course (Peters, 1979). In particular, the value of such R\&D programs can increase by insightful and integrative leaders based on innovation. Therefore, insightful R\&D leaders' integrative perspective and capability lie at the heart of the path-creating and disruptive innovation process. The success of knowledge-based transition economies depends on the effective training of such insightful R\&D leaders. The management of technology and innovation is widely diffused in transition economies such as China, South Korea, Taiwan, Singapore, Indonesia, India, and other catch-up countries.

\section{R\&D Leaders' Emotional Intelligence: Their Fluent Emotional Capital to Integrate Various Types of Knowledge}

Emotional intelligence, which has been referred to as emotional capital (based on the term "intellectual capital"), plays a key role in the management of large and complex R\&D programs in knowledge-based transition economies. Fluent emotional capital can be a good source of innovation. In labor economics, human capital deals mainly with intellectual capital, that is, an individual's capability to search, understand, and learn, among others. However, to explain the development strategies of catch-up countries or transition economies, previous studies have employed the term "collective learning," which refers to an efficient division of (R\&D) labor and collective learning in industrial (R\&D) fields. Collective learning has been a key success factor in catch-up countries such as Korea, Taiwan, and Singapore in semiconductor and automobile industries.

Emotional capital overlaps with social capital, which derives from collaboration and effective relationship management. Human capital and intellectual capital reside in individualoriented human resources and are measured at the individual level. However, social capital resides in relationships and networks. Therefore, emotional capital refers to the relational capability of leaders or R\&D members to face huge emotional burdens from relationships and organizational networks of innovation. Inspirational R\&D leaders may create a chaotic workplace with highly charged emotional peaks and valleys (Zaleznik, 1992). The effectiveness of emotional intelligence has been found to be twice that of technical skills or IQ in job performance at all levels. Nearly $90 \%$ of the difference in profiles of employees in senior leadership positions can be explained by their emotional intelligence, not their cognitive ability (Goleman, 1998). This principle can be applied to R\&D and innovation management. Empathy toward (and understanding) research themes and methodologies of talented R\&D personnel plays an important role in the retention of talented employees. R\&D leaders need to show empathy to develop and retain good employees and thus require a clear understanding of themes and methodologies of those employees. Social skills allow R\&D leaders to take advantage of their emotional intelligence (Goleman, 1998). The empathy shown by inspirational R\&D leaders may not be the kind widely described in the management literature. That is, effective leaders may manage through a unique approach, namely "tough empathy," which refers to giving R\&D members what they need, not what they want (Goffee \& Jones, 2000). R\&D leaders' emotional intelligence plays an important role as glue in interdisciplinary or transdisciplinary research.

Knowledge management in cross-functional teams can be an important factor influencing the success of multidisciplinary project management. In particular, the emotional capital for integrating and communicating with $\mathrm{R} \& \mathrm{D}$ team members is critical to disruptive and path-creating innovation (Huang \& Newell, 2003). Emotional capital can be more important than technical skills when facing and integrating unfamiliar multidisciplinary situations. Emotional capital is a distinct element of social capital. Satisfaction with collaboration, the resolution of conflicts, trust,

April/May 2013 | 51 
and respect are all open to criticism, and transdisciplinary integration can outweigh inconvenience (Mâsse et al., 2008).

\section{R\&D Leaders' Integrity}

In the age of social capital accumulation, the most important factor in innovation may be a sense of humility and obligation toward others regardless of whatever talent or management experience (Eckert, 2001). R\&D evolves from R\&BD (research and business development) into R\&SD (research and solution development or research and social development), in which innovation leaders' integrity can be the most important factor in integrating various innovation efforts. $R \& D$ leaders face ordinary emotional stress every day, and therefore their integrity can strengthen organizational innovation (Peace, 2001; Song et al., 2007). In this regard, forgery, plagiarism, and misconduct should never be allowed in innovation management. R\&D leaders' integrity lies at the heart of CSR (corporate social responsibility). However, a lack of integrity and thus the resulting lack of trust from peers may prevent a leader from reaching the top position (Sorcher \& Brant, 2002). In fact, a strong sense of personal humility is far more evident in exceptional innovation leaders than raw ambition.

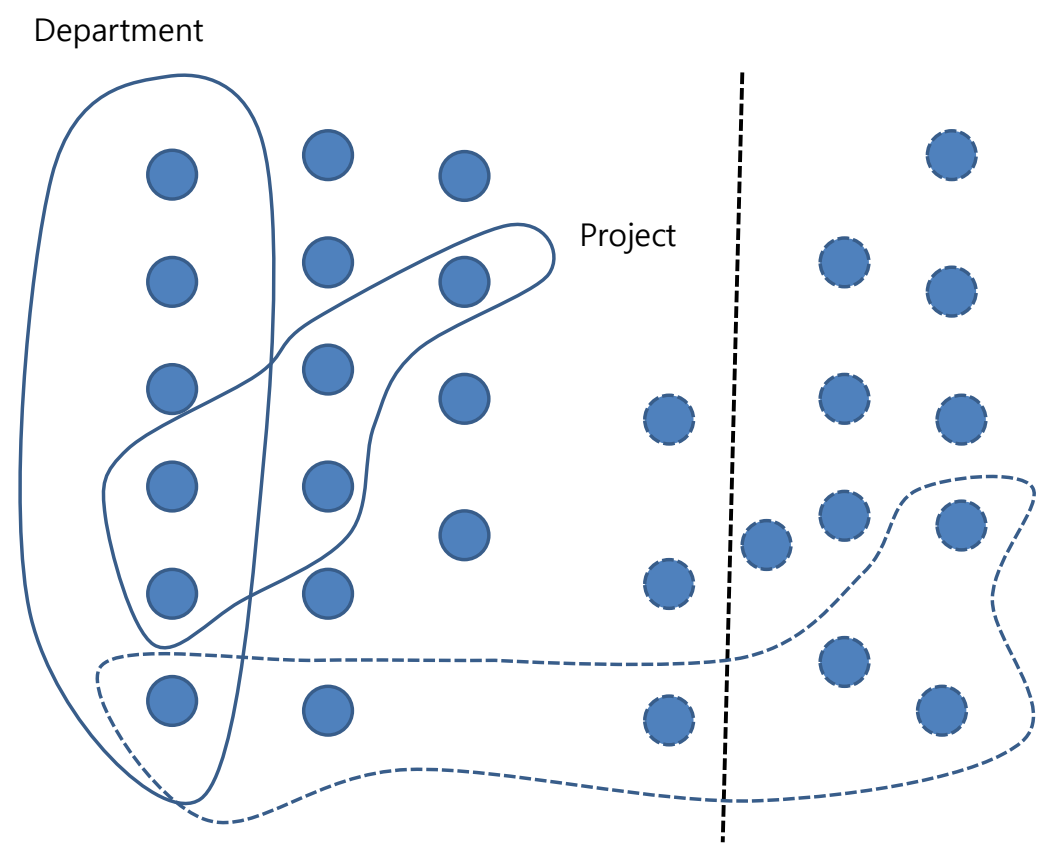

Figure1. A Matrix of Teams and Brokers

\section{Brokering and Hub Positioning in Integration}

\section{Value of Brokering}

How can the social network analysis augment research on leadership in transdisciplinary and multidisciplinary teams? Here brokering and deciphering are important factors. Brokers with cul- 
tural and contextual fluency can serve as translators, interpreters, and moderators to facilitate collaboration and alliances across cultural boundaries. Cultural fluency refers to "recognizing identities and inviting divergent ways of making meaning into organization's awareness" and is a good source of path-creating innovation (Gray, 2008; Park \& Lee, 2011). Boundary management by a broker reflects intra-personal, interpersonal, organizational, institutional, technological, political, and social factors (Figure 1).

\section{Value of Neutrality}

R\&D managers are driven to work long hours and can be forced to do many scattered tasks in a superficial manner. In this sense, brevity, fragmentation, and verbal communication characterize their work. Until recently, the liaison role of $R \& D$ managers, that is, their contact outside the vertical chain of command, has received little attention (Mintzberg, 1990). These managers are positioned at the center of the innovation network, and in all cases, their interpersonal, informational, and decisional roles remain inseparable.

R\&D managers tend to adopt impersonal attitudes toward goals. Innovation management goals arise from the objective need, not from subjective desires. Therefore, R\&D managers attempt to strike a balance between conflicting values and objectives when pursuing solutions. R\&D managers engage in various activities with other members and maintain a low level of emotional involvement in these relationships. These two themes may seem paradoxical, but their coexistence supports what R\&D managers do, including reconciling differences, seeking compromises, and establishing a balance of power. These are important drivers of multidisciplinary and trans-disciplinary research (Mintzberg, 1990). To those R\&D leaders overeducated in management and undereducated in leadership, the idea of getting people moving in the same direction may appear to be an organizational problem. However, what they should do is not to organize people, but to align them (Kotter, 1990).

\section{Team Culture and Characteristics}

\section{Dual-Loop Learning}

R\&D leaders and members showing poor innovation performance tend not to encourage individual accountability. In addition, they avoid revealing potentially threatening or embarrassing but honest information that can motivate learning and facilitate real change and path-creating innovation (Argyris, 1994). In their pursuit of positive thinking and a warm atmosphere, R\&D leaders may deprive members as well as themselves of opportunities to take responsibility for their own behavior by learning to understand it. Because double-loop learning depends on questing one's own assumptions and behaviors (reflection), which is crucial in path-breaking or pathcreating innovation, this seemingly benevolent strategy actually hinders learning and thus disruptive innovation.

Although being considerate and positive can foster solutions to single-loop problems such as cutting costs of production and technological innovation, it does not facilitate pathbreaking innovation and can never go beyond a single paradigm. Therefore, R\&D managers may not really understand why they face problems year after year, why they cover up problems, and why they cover up the cover-up (Argyris, 1994). The TQMI (total quality management of innovation) concept's rigorous, linear reasoning solves a set of important single-loop problems in 
terms of optimization, efficiency, and productivity. However, although there may be some effective single-loop learning, no double-loop learning can occur. Knowledge-based transition economies such as South Korea, Taiwan, China, and perhaps even Japan seriously lack this feature. In fact, what we call defensive reasoning serves no purpose except for self-protection, although those who use it rarely acknowledge that they are protecting themselves (Argyris, 1994). The purpose of this strategy is to avoid vulnerability, risk, embarrassment, and the appearance of incompetence, and therefore it can never foster path-breaking innovation. Organizations' defensive routines are common in technological innovation processes, particularly in the context of transition economies in Asia.

\section{Experience Trap of Uni-Disciplinary Research and the Best-Practice Approach}

Mental models and habitual responses play important roles in the incremental innovation flow. R\&D members and organizations exacerbate estimation problems by basing their model assumptions on data from past projects without first scrubbing them. Not surprisingly, the resulting estimates tend to be unreliable and have little credibility with R\&D project managers. When they lack faith in estimates of main parameters, $R \& D$ project managers are likely to rely on their own perceptions, which can be disastrous. This is an area in which simplistic benchmarking based on "best practices" of successful project managers can be dangerous (Sengupta et al., 2008). Project managers should depend on present data, and not on their perceptions.

Two of the most common and dangerous motives in innovation management are the desire for control and that for importance (Heifetz \& Linsky, 2002). Here the danger is that R\&D leaders can develop an inflated view of themselves and their knowledge and perceptions. Adaptive versus technological changes can be compared. R\&D members tend to resist adaptive changes, to which they need to become accustomed. Therefore, they may even deny the existence of problems and thus a need for some adaptive change because even those not directly affected by an adaptive change typically experience some discomfort or inconvenience when innovators upset the peaceful equilibrium in a group or organization. The circulation of individuals reflects a type of revolving door allowing for the introduction of viable ideas from one sphere to another through the flow of people. In this regard, reciprocity between factors and the equality of contributions to innovation may be important factors enhancing itself in a reflexive manner and facilitating adaptive changes (Dzisah \& Etzkowitz, 2009).

\section{Balance Between the Depth and Width of Networks and Searches}

The depth and width of searches can be defined in various ways. In terms of patent research, the search depth is measured by the number of times a firm repeatedly uses citations in patents it applies for, and the search scope is measured as the "number of citations found in the focal year that cannot be found in the list of patents and citations for the firm in the last five years (Katila \& Ahuja, 2002; Lee \& Lee, 2010).

There are many important reasons why the optimal depth and width of searches are critical. First, there may be too many ideas for the firm to manage and choose from ("the absorptive capacity problem"). Second, many innovative ideas may come at the wrong time and in the wrong place to be fully exploited ("the timing problem"). Third, because there are many ideas, few ideas are taken seriously or given the required level of attention or effort for implementation (“the attention allocation problem") (Koput, 1997; Laursen \& Salter, 2006) 
Exploitive inter-organizational collaboration aims at improving existing technologies and products, whereas explorative interorganizational collaboration focuses on developing new ones. Based on previous research, we consider collaboration with customers and suppliers to be exploitation-oriented (Tripsas, 1997). Collaboration with subjects in the value chain is linked to exploitation and incremental innovation (Faems et al., 2005). Exploration-oriented collaboration is a type of collaboration with universities and GRIs (government research institutes). Therefore, the strategic depth and width of searches and networks should be sought continuously.

Table 1. Typology of Contextual Factors Influencing Multidisciplinary and Transdisciplinary Scientific Collaboration (Stokols et al., 2008)

\begin{tabular}{|c|c|}
\hline \multirow[t]{3}{*}{ Intra-personal } & $\begin{array}{l}\text { Members' attitudes toward collaboration and their willingness to devote substantial } \\
\text { time and effort to transdisciplinary activities }\end{array}$ \\
\hline & $\begin{array}{l}\text { Members' preparation for the complexities and tensions inherent in transdisciplinary } \\
\text { collaboration }\end{array}$ \\
\hline & Participatory, inclusive, and empowering leadership style \\
\hline \multirow[t]{5}{*}{ Interpersonal } & Members' familiarity, informality, and social cohesiveness \\
\hline & Diversity of members' perspectives and abilities \\
\hline & $\begin{array}{l}\text { Ability of members to adapt flexibly to changing task requirements and environmental } \\
\text { demands }\end{array}$ \\
\hline & $\begin{array}{l}\text { Regular and effective communication among members to develop common ground and } \\
\text { consensus about shared goals }\end{array}$ \\
\hline & $\begin{array}{l}\text { Establishment of a hospitable conversational space through mutual respect among team } \\
\text { members }\end{array}$ \\
\hline \multirow[t]{5}{*}{ Organizational } & Presence of strong organizational incentives to support collaborative teamwork \\
\hline & $\begin{array}{l}\text { Nonhierarchical organizational structures to facilitate team autonomy and participatory } \\
\text { goal setting }\end{array}$ \\
\hline & $\begin{array}{l}\text { Breadth of disciplinary perspectives represented within the collaborative team or or- } \\
\text { ganization }\end{array}$ \\
\hline & $\begin{array}{l}\text { Organizational climate of sharing (e.g., sharing of information, credit, and decision- } \\
\text { making responsibilities is encouraged) }\end{array}$ \\
\hline & $\begin{array}{l}\text { Frequent scheduling of social events, retreats, and other center wide opportunities for } \\
\text { face-to-face communication and informal information exchange }\end{array}$ \\
\hline \multirow[t]{4}{*}{ Physical/Environmental } & $\begin{array}{l}\text { Spatial proximity of team members' workspaces to encourage frequent contact and } \\
\text { informal communication }\end{array}$ \\
\hline & Access to comfortable meeting areas for group discussion and brainstorming \\
\hline & $\begin{array}{l}\text { Availability of distraction-free work spaces for individualized tasks requiring concen- } \\
\text { tration and confidentiality }\end{array}$ \\
\hline & $\begin{array}{l}\text { Environmental resources (e.g., sound masking, closable doors and workstation panels) } \\
\text { to facilitate members' regulation of visual and auditory privacy }\end{array}$ \\
\hline
\end{tabular}

\section{Familiarity and Differentiation}

R\&D team members' familiarity with one another, their social cohesiveness, and group size play critical roles in the innovation process. Previous psychological and organizational research on team science has demonstrated the importance of differentiation and diversity in terms of individuals' gender, religion, knowledge, location, race, age, and disciplinarity. Transdisciplinary conceptual frameworks reflect a higher degree of integration achieved through interdisciplinary collaboration.

It is the paradoxical blend of personal humility and strong professional will that enables some individuals to become exemplary leaders (Collins, 2001). Good communication between R\&D team members encourages feelings of trust and psychological safety and enables teams to 
better manage various issues associated with their size, compatibility, and cohesion. Teams perform best when their tasks and outcomes are purely group- or individual-oriented. However, hybrid teams perform poorly, exhibit weak interpersonal processes, and show low levels of member satisfaction (Stokols et al., 2008).

Community coalitions and interorganizational collaboration between scientists and practitioners may translate scientific findings into interventions and programs that can promote public health and social justice. Practitioners' goals are more pragmatic, community-oriented, and favorably disposed to quickly determining and implementing problem-solving strategies, whereas researchers generally have a longer-term orientation, are more concerned about basic research questions, and aim at publishing findings and receiving grants (Stokols et al., 2008). By contrast, those emphasizing secrecy, in-group exclusiveness, and confrontation can weaken cooperative problem solving among members and minimize their use of intellectual resources. In interorganizational and inter-sectoral coalitions, the presence of multiple program champions who are well known and respected among partners can facilitate coordination across participating organizations.

\section{Path-Creating Innovation Factors}

\section{Decentralized Organizations and the Spirituality of Innovation}

Creative R\&D work is motivated mainly by a sense of joy, not by fear or severe competition, which, as the Weberian analysis suggests, is the case in contemporary society and often associated with the present R\&D life (Gabriel, 1999; Ericsson et al., 2007). Types of organizations' hierarchical structures and cultures play important roles in multidisciplinary and transdisciplinary research. In large and complex R\&D programs, monitoring and control (top-down management style) are necessary for their directional alignment and coordination. However, compared with decentralized methods that reinforce teamwork and a sense of community, the organizational governance of monitoring and control is not particularly effective in multidisciplinary R\&D projects, as shown in Figure 2. Voluntary R\&D personnel's participation in major decisions can substantially enhance the efficacy of autonomy. A fair distribution of burdens and benefits of R\&D work is also important (Porth \& McCall, 1999; Huckman, 2009).

Toyota has been found to maximize R\&D personnel's creativity by developing new technologies, marketing strategies, and supply chains. By encouraging employees to experiment, Toyota has gone beyond its comfort zone into uncharted territory (Takeuchi et al., 2008; Nidumolu et al., 2009), finding that one of the best ways to ensure good communication in the innovation process is to have all members work together in one large room with no partitions, which facilitates the Japanese style of collective learning. In providing sufficient autonomy and freedom for a creative atmosphere, Toyota has faced serious electromechanical problems. This raises the question of whether such problems derive from firm cultures emphasizing voluntariness and autonomy. In addition, monitoring and control policies should be strengthened in Toyota. There is clearly some tension between an innovator's independent mindset and their social involvement with colleagues, but the ability to seamlessly shift between isolation and a larger group is essential (Cohn et al., 2008). 
Figure 2. Formulation of Multidisciplinary R\&D Organizations: Simple vs. Complex Layers

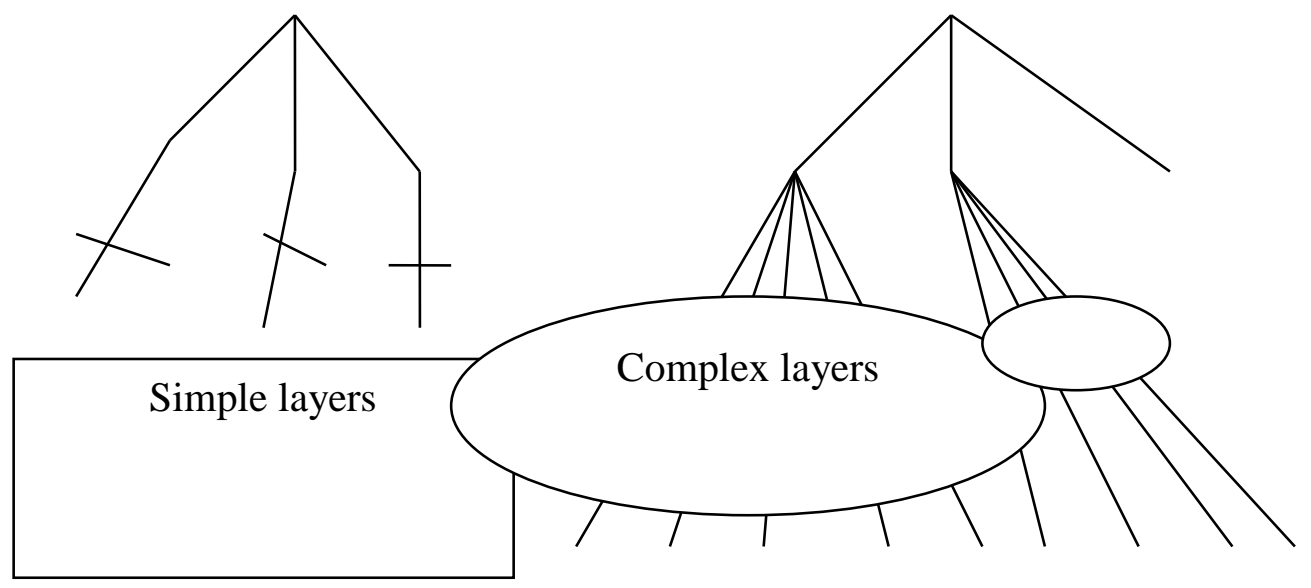

Figure 3. Innovation Value Chain (Figure Based on Nambisan \& Sawhney, 2007)

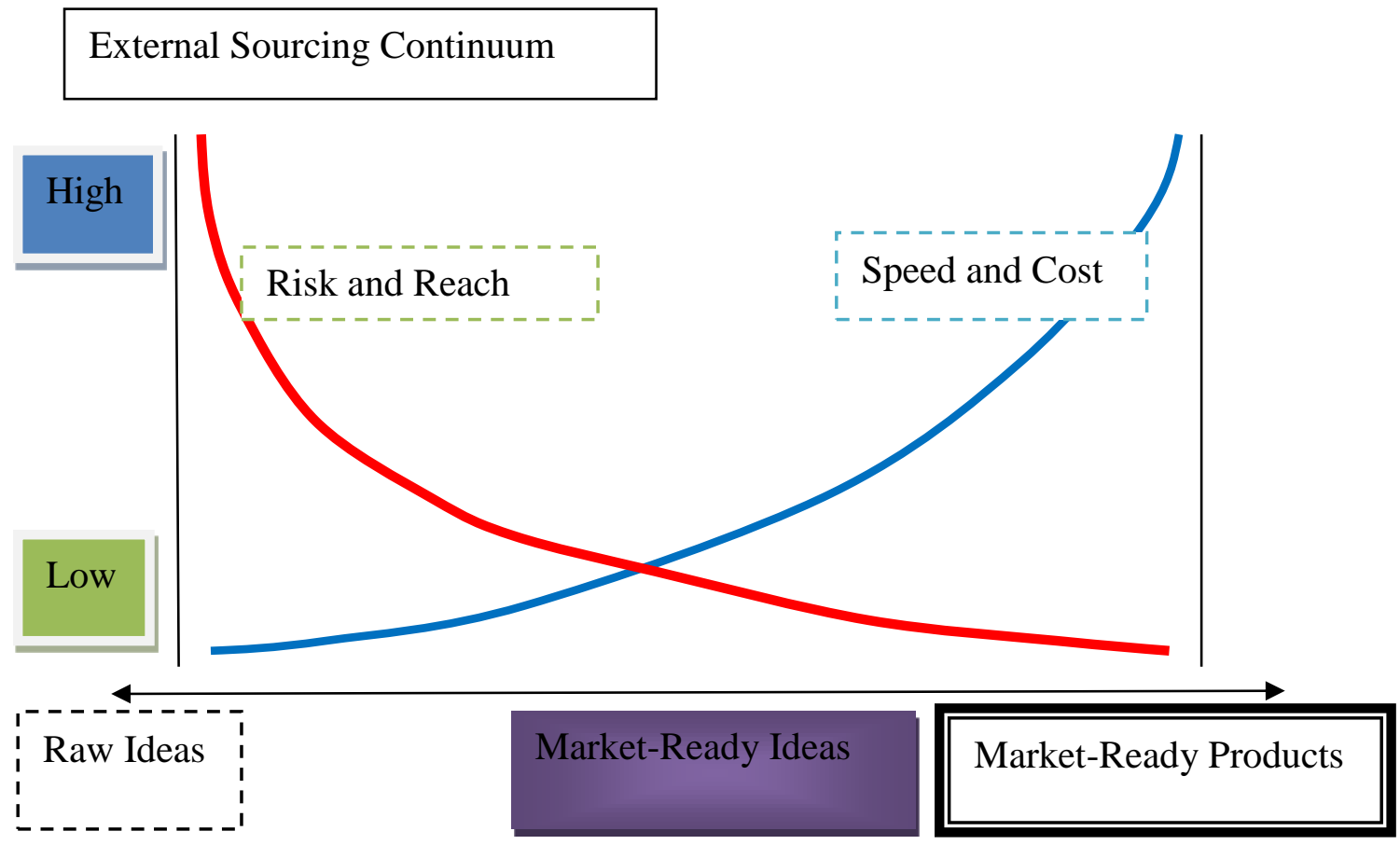

\begin{tabular}{|l|l|}
\hline - Licensing Agent & - Innovation \\
- Patent Broker & Capitalist \\
- Electronic R\&D & \\
- Marketplace & \\
- Idea Scout & \\
- Invention Capitalist & \\
\hline
\end{tabular}

- Internal Business Incubator

- External Business Incubator

- Venture Capitalist 
Large pharmaceutical firms' R\&D organizations can serve as a good example of a simple hierarchical structure. The most important phenomenon is the breakup of formerly mammoth R\&D organizations into small cross-disciplinary or multidisciplinary groups, each of which focusing on a family of related diseases (Garnier, 2008; Kim \& Mauborgne, 2009). There are only two or three management layers between each center's CEO and key bench scientists. Complexity and a lack of leadership can give rise to teams focusing too much on maintaining processes and too little on producing meaningful results (Garnier, 2008). For scientists to feel a sense of ownership, resource allocation should be reinvented such that teams have to compete for funding. The capability to conduct rigorous patent reviews, which is critical in pharmaceutical $R \& D$, should be strengthened to help teams find their fields of research. The approaching wave of patent expiration leaves them little time and space. Cisco's idea contest is also a good example of open innovation. Here a team of six employees works full-time on an idea for three months (Jouret, 2009).

Table 2. Innovation Strategy (Table Based on Nambisan \& Sawhney, 2007)

\begin{tabular}{|c|c|c|c|c|}
\hline Factors & Subfactors & Shop for Raw Ideas & $\begin{array}{c}\text { Shop for Market-Ready } \\
\text { Ideas }\end{array}$ & $\begin{array}{l}\text { Shop for Market-Ready } \\
\text { Products }\end{array}$ \\
\hline \multirow[t]{5}{*}{$\begin{array}{c}\text { Industry/Market } \\
\text { Factors }\end{array}$} & $\begin{array}{l}\text { Pace of technological and } \\
\text { market change }\end{array}$ & Low & Medium & High \\
\hline & $\begin{array}{l}\text { Intellectual property con- } \\
\text { text }\end{array}$ & Well-defined IP rights & $\begin{array}{l}\text { Roughly defined IP } \\
\text { rights }\end{array}$ & Poorly defined IP rights \\
\hline & $\begin{array}{l}\text { Market potential for typical } \\
\text { innovation }\end{array}$ & $<\$ 100 \mathrm{M}$ revenues & $\begin{array}{l}\$ 100 \mathrm{M} \sim \$ 500 \mathrm{M} \text { reve- } \\
\text { nues }\end{array}$ & $>\$ 500 \mathrm{M}$ revenues \\
\hline & $\begin{array}{l}\text { Cost of evaluating typical } \\
\text { innovation }\end{array}$ & $\begin{array}{l}\text { Low (ideas can be tested } \\
\text { in isolation) }\end{array}$ & $\begin{array}{l}\text { Medium (detailed mar- } \\
\text { ket/technology assess- } \\
\text { ments required) }\end{array}$ & $\begin{array}{l}\text { High (extensive infra- } \\
\text { structure required) }\end{array}$ \\
\hline & $\begin{array}{l}\text { Information required to } \\
\text { develop typical innovation }\end{array}$ & $\begin{array}{l}\text { Specific innovation } \\
\text { knowledge }\end{array}$ & $\begin{array}{l}\text { Integrated knowledge } \\
\text { from different functional } \\
\text { areas }\end{array}$ & $\begin{array}{l}\text { Complex and integrated } \\
\text { knowledge from differ- } \\
\text { ent technologies and } \\
\text { markets }\end{array}$ \\
\hline \multirow[t]{6}{*}{ Firm Factors } & Purpose of innovation & $\begin{array}{l}\text { Enhancement of exist- } \\
\text { ing products }\end{array}$ & $\begin{array}{l}\text { New products and brand } \\
\text { extensions }\end{array}$ & $\begin{array}{l}\text { New markets and rede- } \\
\text { fined product portfolios }\end{array}$ \\
\hline & Innovation capabilities & $\begin{array}{l}\text { Strong development and } \\
\text { commercialization }\end{array}$ & $\begin{array}{l}\text { Moderate development } \\
\text { and strong commerciali- } \\
\text { zation }\end{array}$ & $\begin{array}{l}\text { Weak development and } \\
\text { strong commercializa- } \\
\text { tion }\end{array}$ \\
\hline & Product portfolio & $\begin{array}{l}\text { Large number of diverse } \\
\text { products }\end{array}$ & $\begin{array}{l}\text { Products in a few key } \\
\text { markets }\end{array}$ & $\begin{array}{l}\text { Products in a few key } \\
\text { technology domains }\end{array}$ \\
\hline & Firm size & Medium & Medium to large & Large \\
\hline & Risk appetite & High & Medium & Low \\
\hline & Innovation portfolio & $\begin{array}{l}\text { Weak; needs externally } \\
\text { sourced ideas }\end{array}$ & $\begin{array}{l}\text { Complementary to ex- } \\
\text { ternally sourced ideas }\end{array}$ & $\begin{array}{l}\text { Weak; needs externally } \\
\text { sourced products }\end{array}$ \\
\hline
\end{tabular}

\section{Innovation Value Chain}

$\mathrm{P} \& \mathrm{G}$ has employed the strategy of acquiring fully developed and market-tested products to reduce innovation risk and the time to market, which can come with higher acquisition costs and a narrower range of options (Nambisan \& Sawhney, 2007). From idea generation to conversion and then to diffusion, a very short innovation value chain has been considered (Figure 3 ).

It is critical to fix idea-poor organizations. R\&D personnel tend to talk to their close colleagues, not to their counterparts in other departments or divisions. For example, when a senior R\&D executive in an innovation-based venture identifies an innovative idea, they should gain personal control of it and accelerate it through the system if they want to commercialize it quickly. If they want to kill an idea, then they should send it through the formal process. Therefore, 
multichannel idea processes and funding play important roles in the innovation process, even in venture firms (Hansen \& Birkinshaw, 2007). Table 2 shows the choice of innovation-sourcing strategies.

\section{Clearness of Vision, Intrinsic Motivation, and Action Alignment}

It is clear that managing for the short term comes at the expense of long-term firm value (Mizik \& Jacobson, 2007). If the R\&D team leader proposes more concrete goals, then R\&D employees are able to exercise their full potential more effectively. An optimal level of R\&D goal clearness is crucial for the realization of R\&D personnel's potential. Mismatches between rewards stressing disciplinary competence over innovation and institutional disincentives can prevent successful multidisciplinary and trans-disciplinary R\&D endeavors. R\&D members may be disappointed because they may perceive some misalignment between the direction of the R\&D team and their own aspirations. Previous studies have observed an advantage of intra-tier partnerships for tier II and tier III (Jones et al., 2008).

\section{Discussion and Policy Implications}

\section{Large and Multidisplinary/Transdisciplinary Programs and R\&D Organizations}

Researchers prefer independent research with a high degree of freedom because they consider it important to determine the direction of research and solutions on their own. However, governments of developing countries are likely to control public R\&D through various R\&D policies. Therefore, researchers tend to be tied to government policies and control, and their favorable R\&D behaviors toward independent research and government policies can produce a number of redundant, small, and overlapped R\&D programs in the public R\&D domain in transition economies.

In addition, noncreative $R \& D$ organizations tend to be large and rigid and thus are less likely to quickly adapt to environmental changes. Their research areas and methodologies are too specifically defined and settled to efficiently accommodate rapid technological changes. Engineering schools of large universities in South Korea, China, Japan, and other Asian countries tend to form such R\&D organizations. This raises the question of whether such organizations produce innovative multidisciplinary/transdisciplinary research outcomes. Although they may not, they require critical reformation.

In general, creative R\&D organizations tend to be small and composed of six or eight members. Effective and frequent communication between members can be a creative source of ideas. Therefore, trans-disciplinary and multidisciplinary research programs should be composed of small autonomous teams with a high degree of freedom. As shown in Figure 4, a large R\&D group can include several small subgroups A, B, C, and D with a high degree of R\&D freedom. 
Figure 4. Ideal Multidisciplinary R\&D Organization

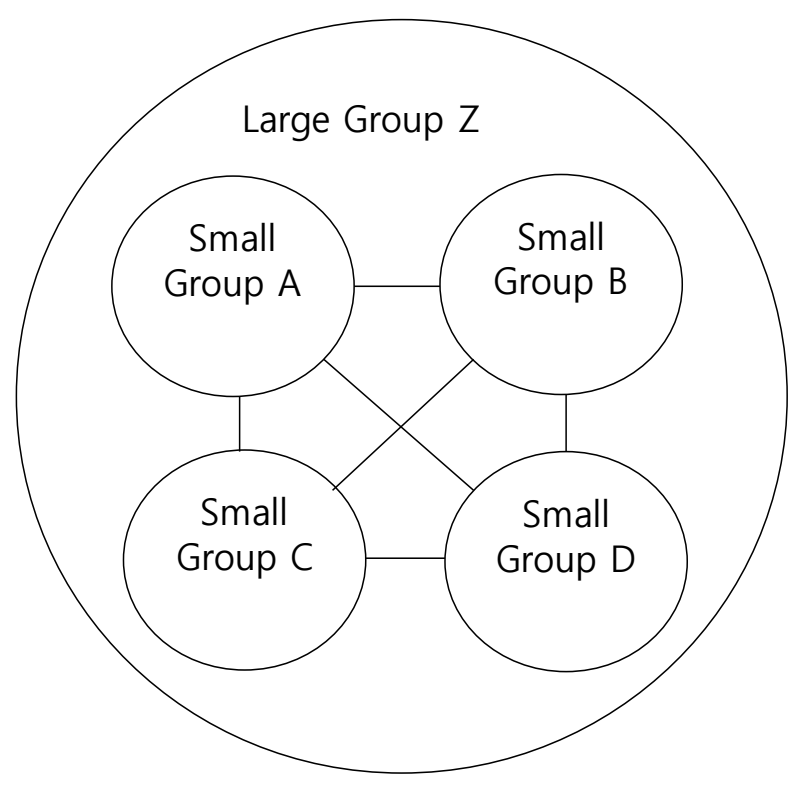

The issue of how small teams in multidisciplinary organizations can be effectively integrated can be raised in the management of large and complex R\&D projects. For example, national $R \& D$ projects with large and complex subprograms such as the implementation of the space shuttle program, the development of a new flu vaccine, and the management of river quality require a strict R\&D management style. Maybe large non-R\&D projects can provide some clues for the solution.

\section{Government-Sponsored Research Institutes’ Mission in Transition Economies}

Creative research with path-creating or path-skipping attributes (Lee \& Lim, 2001) in large and complex R\&D programs can be the major mission of government-sponsored research institutes in transition economies. Here trans-disciplinary research can be a key driver of innovation in transition economies. Frontiers of emerging technologies can be extended by such R\&D.

For creative research, individual-based small research should to be encouraged, and then such research should lead to large and complex research programs. Korea's public sector is more likely to have difficulty engaging in small research than universities. Korea's government-sponsored research institutes (GRIs) are in charge of large-scale national agendas built based on a top-down approach. Therefore, GRIs attempt to combine such agendas through small, creative, and autonomous R\&D teams.

\section{Core Capability, Outsourcing, and Open Innovation}

The excessive use of external sources can reduce investment in organizations' internal innovation capability, which can weaken then competitive position. Outsourcing and other external sources can adversely influence the development of tacit and organization-specific knowledge necessary for radical innovation that can yield new knowledge (Zahra \& Nielsen, 2002). 
R\&D managers need to develop strong innovation skills based on human resources to ensure their technological competence. Internal human resources facilitate learning by doing and produce tacit knowledge and critical knowhow, which are more likely to facilitate innovation processes than explicit knowledge, such as academic papers and patents. The strategic value of internal human resources is further highlighted by the weak and negative association observed between HR capability and some technology commercialization measures (Zahra \& Nielsen, 2002). This means that human resources with tacit knowledge and know how play a crucial role in the process of technology commercialization in transition economies. Geographically distributed collaborators often face heavy travel demands and/or endless audio conferences. Remote R\&D collaboration means the "greening" of the R\&D process. Here an important paradigm in internetmediated science is the collaboratory (a "laboratory without walls"), a virtual entity created through computer networks (Teasley \& Wolinsky, 2001).

\section{Acknowledgements}

This research was funded by National Research Foundation (2012R1A1A1012649) and Inha University.

\section{References}

Argyris, C. (1994). Good Communication That Blocks Learning. Harvard Business Review, 72(4), 77-85.

Bettencourt, L. A., A. W. Ulwick (2008). The Customer-Centered Innovation Map. Harvard Business Review, 86(5), 109-114.

Cohn, J., J. Katzenbach, and G. Valk (2008). Finding and Grooming Breakthrough Innovators. Harvard Business Review, 86(12), 63-69.

Collins, J. (2005). Level 5 leadership: The triumph of humility and fierce resolve. Harvard Business Review, 83(7), 136-143.

Dzisah, J. \& Henry Etzkowitz (2009). Triple Helix Circulation: The Heart of Innovation and Development. The $7^{\text {th }}$ Triple Helix conference theme paper, pp. 1-19. Glasgow, 17-19 June.

Ericsson, K. A., M. J. Prietula, E. T. Cokely (2007). The Making of an Expert. Harvard Business Review, 85(7/8), 115-121.

Eckert, R. A. (2001). Where Leadership Starts. Harvard Business Review, 79(10), 53-61.

Faems, D., B. Van Looy, K. Debackere (2005). Interorganizational Collaboration and Innovation: Toward a Portfolio Approach. The Journal of Product Innovation Management, 22, 238250.

Gabriel, I. (1999). Giving meaning to work: the spiritual challenge of our time. The Third International Symposium on Catholic Social Thought and Management Education, Rethinking the Spiritual and Social Life within Business, International Centre, Dona Paula, Goa, India, January $10-12$, pp.1-8.

Garnier, J.-P. (2008). Rebuilding the R\&D Engine in Big Pharma. Harvard Business Review, 86(5), 69-76.

Goffee, R \& Gareth Jones (2000). Why Should Anyone Be Led by You. Harvard Business Review, 78(5), 62-70. 
Goleman, D. (1998). What Makes a Leader? Harvard Business Review, 76(6), 93-102.

Gray, B. (2008). Enhancing Transdisciplinary Research Through Collaborative Leadership. American Journal of Preventive Medicine, 35(2S), S124 - S132.

Hansen, M. T., J. Birkinshaw (2007). The Innovation Value Chain. Harvard Business Review, 85(6), 121-130.

Heifetz, R. A. \& Marty Linsky (2002). A Survival Guide for Leaders. Harvard Business Review, $80(6), 65-74$.

Huang, J. C., S. Newell (2003). Knowledge integration processes and dynamics within the context of cross-functional projects. International Journal of Project Management, 21, 167-176.

Huckman, R. S. (2009). Are You Having Trouble Keeping Your Operations Focused? Harvard Business Review, 87(9), 91-95.

Jones, B. F., S. Wuchty, B. Uzzi (2008). Multi-University Research Teams: Shifting Impact, Geography, and Stratification in Science. Science, 322, 1259-1262.

Jouret, G. (2009). Inside Cisco's Search for the Next Big Idea. Harvard Business Review, 87(9), 43-45.

Katila, R., G. Ahuja (2002). Something Old, Something New: A Longitudinal Study of Search Behavior and New Product Introduction. Academy of Management Journal, 45(6), 1183-1194.

Kim, W.C., R. Mauborgne (2009). How Strategy Shapes Structure. Harvard Business Review, 87(9), 73-80.

Koput K. W. (1997). A Chaotic Model of Innovative Search: Some Answers, Many Questions. Organization Science, 8(5) 528-542.

Kotter, J. P. (1990). What Leaders Really Do. Harvard Business Review, 79(11): 85-96.

Laursen, K., A. Salter (2006). Open for Innovation: The Role of Openness in Explaining Innovation Performance among U.K. Manufacturing Firms. Strategic Management Journal, 27, 131150.

Lee, K. \& C. Lim (2001). Technological regimes, catching-up and leapfrogging: Findings from the Korean industries. Research Policy, 30(3), 459-483.

Lee, Y.-G. (2012). Strengthening Competency Linkage to Innovation at Korean Universities, Scientomertics, 90(1), 219-230.

Lee, Y.-G., J.-H. Lee (2010). Different characteristics between auctioned and non-auctioned patents, Scientometrics, 82(1), 135-148.

Lee, Y.-G. (2010). Sectoral strategic differences of technological development between electronics and chemistry: A historical view from analyses of Korean-invented US patents during the period of 1989 to 1992, Scientometrics, 82(1), 83-92.

Lee, Y.-G., S. Park, Y. Song (2009). Which is Better for a Firm's Financial Performance: An Externally Oriented or Inwardly Oriented Innovation Strategy? An Empirical Study of Korean SMEs. Asian Journal of Technology Innovation, 17 (1), 57-73.

Lee, Y.-G. (2009). What Affects a Patent's Value? An Analysis of Variables That Affect Technological, Direct Economic, and Indirect Economic Value: An Exploratory Conceptual Approach. Scientometrics, 79 (3), 623-633.

Lee, Y.-G., J. Lee, Y. Song, H. Kim (2008). Technological convergence and open innovation in the mobile telecommunications industry. Asian Journal of Technology Innovation, 16 (1), 4562.

Mâsse, L. C., R. P. Moser, D. Stokols, B. K. Taylor, S. E. Marcus, G. D. Morgan, K. L. Hall, R. T. Groyle, W. M. Trochim (2008). Measuring Collaboration and Transdisciplinary Integration in Team Science. American Journal of Preventive Medicine, 35(2S), S151 - S160. 
Mintzberg, H. (1990). The Manager's Job- Folklore and Fact. Harvard Business Review, 68(2), 163-176.

Mintzberg, H. (2007). Productivity Is Killing American Enterprise. Harvard Business Review, $85(7 / 8), 25$.

Mizik, N., R. Jacobson (2007). The Cost of Myopic Management. Harvard Business Review, 85(7/8), 22-24.

Nambisan, S., M. Sawhney (2007). A Buyer's Guide to the Innovation Bazaar. Harvard Business Review, 85(6), 109-118.

Nidumolu, R., C. K. Prahalad, M. R. Rangawami (2009). Why Sustainability Is Now The Key Driver of Innovation. Harvard Business Review, 87(9), 57-64.

Park, S.-h., Y.-G. Lee (2011). Perspectives on Technology Transfer Strategies of Korean Companies in Point of Resource and Capability Based View, Journal of Technology Management and Innovation, 6(1), 161-184.

Peace, W. H. (1991). The Hard Work of Being a Soft Manager. Harvard Business Review, 69(6), 40-44.

Peters, T. J. (1979). Leadership: Sad Facts and Silver Linings. Harvard Business Review, 57(6), 164-172.

Porth, S. J., J. McCall (1999). Contemporary Management Theories and Catholic Social Teaching: A Review and Analysis. The Third International Symposium on Catholic Social Thought and Management Education, Rethinking the Spiritual and Social Life within Business, International Centre, Dona Paula, Goa, India, January 10-12, pp.1-15.

Sengupta, K., T. K. Abdel-Hamid, L. K. Van Wassenhove (2008). The Experience Trap. Harvard Business Review, 86(2), 94-101.

Song, Y., D. Lee, Y.-G. Lee, Y. Chung (2007). Managing uncertainty and ambiguity in frontier R\&D projects: A Korean case study. Journal of Engineering and Technology Management, 24(3), 231-250.

Sorcher, M., Brant, J. (2002). Are You Picking the Right Leaders? Harvard Business Review, 80(2), 78-85.

Stokols, D., S. Misra, R. P. Moser, K. L. Hall, B. K. Taylor (2008). The Ecology of Team Science: Understanding Contextual Influences on Transdisciplinary Collaboration. American Journal of Preventive Medicine, 35(2S), S96 - S115.

Takeuchi, H., E. Osono, and N. Shimizu (2008). The Contradictions That Drive Toyota's Success. Harvard Business Review, 86(6), 96-104.

Teasley, S., S. Wolinsky (2001). Scientific Collaborations at a Distance. Science, 292(5525), 2254-2255.

Tripsas, M. (1997). Unraveling the Process of Creative Destruction: Complementary Asset and Incumbent Survival in the Typesetter Industry. Strategic Management Journal, 18, 119-142.

Zahra, S. A., A. P. Nielsen (2002). Sources of Capabilities, Integration and Technology Commercialization. Strategic Management Journal, 23, 377-398.

Zaleznik, A. (1992). Managers and Leaders: Are They Different? Harvard Business Review, 70(2), 126-135. 